\title{
Single Episode of Major Depressive Disorder
}

National Cancer Institute

\section{Source}

National Cancer Institute. Single Episode of Major Depressive Disorder. NCI Thesaurus.

Code $C 34796$

An episode of depression lasting two or more weeks without an intervening episode of mania. 